\title{
OS DONOS DO SILÊNCIO: A POLÍTICA EXTERNA DO REGIME MILITAR BRASILEIRO E A COMISSÃO DE DIREITOS HUMANOS DAS NAÇÕES UNIDAS ${ }^{1}$
}

\author{
João Roriza \\ aProfessor de Relações Internacionais na Universidade Federal de Goiás. Goiânia, GO, Brasil. \\ E-mail:joaororiz@ufg.br \\ Orcid:0000-0001-8234-9342 \\ http://dx.doi.org/10.1590/0102-103136/113
}

E quando é noite, sempre, uma tribo de palavras mutiladas procura abrigo em minha garganta para que eles não cantem, os sombrios, os donos do silêncio. (Alejandra Pizarnik)

\section{Introdução}

No início da tarde de 25 de fevereiro de 1974, uma ex-primeira-dama de um longínquo país sul-americano foi convidada para uma sessão da Comissão de Direitos Humanos (CDH) da Organização das Nações Unidas (ONU), em Genebra. Dado o impacto de sua presença, os diplomatas

\footnotetext{
1 Este trabalho foi financiado pelo Programa Primeiros Projetos da Fundação de Amparo à Pesquisa do Estado de Goiás (FAPEG). Uma versão anterior foi apresentada no $7^{\circ}$ Encontro da Associação Brasileira de Relações Internacionais (ABRI) em Belo Horizonte, em 25 de julho de 2019. Gostaria de agradecer os valiosos comentários de Alexandre Moreli, Alessandra Castilho, Bruno Boti Bernardi, José A. Lindgren Alves e Matheus de Carvalho Hernandez. As opiniões contidas e os eventuais erros remanescentes são de minha inteira responsabilidade.
} 
debatiam se o evento poderia ou não ser televisionado. Decidiram que sim. O governo de seu marido, identificado com os ideais políticos de esquerda, tinha sido interrompido por um golpe de Estado com apoio dos Estados Unidos, dando início a uma violenta ditadura militar.

Suas palavras eram mais apaixonadas do que aquelas habitualmente ditas no ambiente diplomático. O seu povo, ela disse, tinha sido "roubado de seus direitos fundamentais e a nação estava sofrendo um 'estado de guerra interno' caracterizado por violações diárias e cruéis de cada uma das normas estabelecidas na Declaração Universal dos Direitos Humanos”. Os militares de seu país “perseguiam cidadãos por sua ideologia", acusava ela, "pessoas categorizadas como 'marxistas' eram perseguidas, torturadas e punidas e tinham sua dignidade violada". Em seu discurso, a ex-primeira-dama seguiu com uma lista de violações de direitos específicos da Declaração Universal, tais como tortura, violações sexuais, 104 sequestros, prisões sem julgamentos, fim da liberdade de imprensa. Entre as vítimas, artistas, líderes políticos, sindicalistas, cidadãos comuns. Comparou a crueldade do seu governo à dos fascistas. Por fim, ela pediu que a ONU fizesse algo e que a $\mathrm{CDH}$ condenasse os militares por violações de direitos humanos (United Nations, 1974, p. 54-58).

A ex-primeira-dama que impactou os membros do principal órgão de direitos humanos da ONU não era a também exilada Maria Thereza Fontella Goulart; mas sim Mercedes Hortensia Bussi Soto de Allende, ex-primeira-dama do Chile. À época, vice-presidente da ONG Federação Democrática Internacional das Mulheres, usava sua notoriedade para denunciar o golpe e as atrocidades cometidas pelos militares, ao contrário da ex-primeira-dama brasileira, mais discreta. Sua fala foi seguida de manifestações contundentes de solidariedade por parte da URSS, Bulgária, Iugoslávia, Tchecoslováquia e Polônia. Os socialistas classificaram o governo que depôs Allende como uma "ditadura fascista", 
acusaram-no de violar sistematicamente os direitos humanos e instaram a interferência da CDH. Alguns ocidentais, como os Países Baixos, juntaram-se aos críticos (MRE, 1974b). No ano seguinte, a CDH estabeleceu o grupo especial de peritos para lidar com violações ocorridas no Chile, o primeiro grupo que não tinha relação com questões de racismo e ocupação estrangeira. A condenação contra a ditadura chilena rompia fronteiras bipolares e a linguagem usada era a de violações de direitos humanos.

Naquela mesma tarde de fevereiro, diplomatas de outra ditadura militar também lidavam com acusações de direitos humanos na ONU. Telegramas da representação diplomática do Brasil em Genebra eram enviados para Brasília, discutindo quais seriam as melhores estratégias frente a um enorme dossiê contra o país que circulava na CDH. Há algum tempo, ONGs como a Anistia Internacional e outras associações denunciavam a ditadura, e com uma nova resolução na $\mathrm{CDH}$, havia naquele momento uma chance significativa de o caso contra o país prosperar. Ser condenado pela principal organização internacional por assassinatos, tortura, desaparecimentos e prisões arbitrárias seria péssimo para a administração de Ernesto Geisel que conduzia rigorosamente o processo de abertura política.

Os casos contra as ditaduras do Chile e do Brasil na Comissão de Direitos Humanos tiveram rumos e resultados opostos. As iniciativas contra o primeiro significaram um momento de consolidação da pressão internacional contra o país, contribuíram para o seu isolamento diplomático, publicizaram internacionalmente as violações da ditadura de Pinochet, além de posicioná-lo dentro de um enquadramento que será um dos alvos preferidos da diplomacia de Jimmy Carter. A CDH ajudou a marginalizar e a denunciar a ditadura chilena (Kelly, 2018). O caso brasileiro é bastante distinto, as iniciativas contra a ditadura brasileira não prosperaram em Genebra e Nova York. Pouco ainda se conhece 
sobre a história de quando a ditadura foi objeto de escrutínio na ONU. Enquanto o caso chileno é trabalhado nas literaturas de história, relações internacionais e direitos humanos, as raras menções sobre o caso brasileiro (Belli, 2009; Cançado Trindade, 2000) oferecem poucos detalhes sobre seu trâmite e significado. Esses trabalhos podem dar uma impressão que enfatiza as deficiências institucionais da ONU e minimiza as estratégias diplomáticas brasileiras.

Não foram poucas as críticas à atuação da $\mathrm{CDH}$, e que a entenderam como uma instituição ineficiente, parcial e irrelevante. De fato, frente a muitas situações, a CDH era um exemplo da inércia onusiana, por design institucional e vontade política de seus membros. Todavia, isso é apenas parte da história. Quando visto a partir dos documentos do MRE, outro lado é desvendado: a diplomacia da ditadura atuou de forma diligente e eficiente para silenciar todas as críticas contra o país na ONU. ${ }^{2}$ A política externa de Geisel tinha receio que o caso contra o país avançasse - ainda mais no contexto delicado do início da distensão política.

Parte dos trabalhos tradicionais de política externa da ditadura militar minimiza ou desconsidera as relações entre o caráter autoritário do regime e sua atuação internacional. Contra essa corrente, uma literatura crescente busca entender de forma crítica a diplomacia da ditadura e suas conexões com a repressão. Há trabalhos sobre os casos contra o regime no sistema interamericano (Bernardi, 2017; Maia e Lima, 2017), as disputas de narrativas em torno dos direitos humanos (Roriz, 2017), os impactos institucionais da ditadura no próprio Itamaraty (Almeida, 2008; Batista, 2010; Carmo, 2018), a atuação do Centro de Informações

\footnotetext{
${ }^{2}$ Estratégias similares foram usadas pela política externa brasileira no sistema da OEA. Na Comissão Interamericana de Direitos Humanos da OEA, todavia, o Brasil não conseguiu impedir sua condenação em dois casos importantes, o 1683 e o 1684. Sobre a atuação da Comissão Interamericana durante a ditadura brasileira, ver o trabalho de Bernardi (2017).
} 
do Exterior (Ciex) (Penna Filho, 2009; Setemy, 2013; Castilho, 2015; Prado, 2017) e as conexões com outras ditaduras (Harmer, 2012), como a uruguaia (Fernandes, 2018) e a chilena (Fernandes, 2007; Marques, 2014; Simon, 2021). Todavia, as denúncias contra a ditadura na ONU não tiveram muita atenção.

Neste artigo, trato do principal caso contra o regime militar que tramitou entre 1974 e 1976 na Comissão de Direitos Humanos da ONU. Nos arquivos da ditadura, os diplomatas se referiam a um "dossiê", um documento que reunia diversas denúncias, e cujo âmago foi um relatório preparado pela Anistia Internacional com uma lista de mais de 1.000 vítimas e 472 perpetradores de torturas, homicídios e prisões políticas ocorridas entre 1968 e 1972, os "anos de chumbo". O caso foi a principal ameaça contra a ditadura militar no sistema ONU e o que mais mobilizou a diplomacia do regime.

As principais fontes que utilizei foram os documentos secretos e confidenciais do Ministério das Relações Exteriores, coletados no arquivo de Brasília. Há também algumas referências a outros documentos do arquivo da CDH em Genebra e do acervo do CPDOC. Antes de passar ao caso contra o Brasil e às reações da diplomacia da ditadura, exponho, na seção seguinte, a Comissão e sua atuação.

\section{A Comissão de Direitos Humanos da ONU}

Os direitos humanos têm uma trajetória ambígua na ONU. Enquanto alguns aludem às suas (breves) menções na Carta, na Declaração Universal e na Convenção de Genocídio como fundamentos de uma nova normatividade, outros contextualizam o cenário de colonização, suas prioridades securitárias ou mesmo seus arranjos com a ordem econômica (Mazower, 2009). Desde cedo, foram uma questão em disputa, o que também marcou a Comissão de Direitos Humanos, estabelecida em 1946 no âmbito do 
Conselho Econômico e Social (Ecosoc). O foco inicial da $\mathrm{CDH}$ era a realização de estudos e recomendações, principalmente documentos que pudessem tornar-se tratados de direitos humanos (United Nations, 1946). Dentre seus trabalhos legislativos estão incluídas as redações da Declaração Universal dos Direitos Humanos de 1948 e os dois Pactos Internacionais de $1966 .{ }^{3}$ Para auxiliar seu funcionamento, o Ecosoc sugeriu a criação de subcomissões. ${ }^{4}$ Interessa-me aqui a Subcomissão de Prevenção da Discriminação e Proteção de Minorias (doravante Subcomissão), criada em 1947, uma vez que o caso contra o Brasil tramitou nela. Suas atribuições incluíam a realização de estudos e recomendações, além de eventuais novas funções a pedido da $\mathrm{CDH}$ (United Nations, 1949).

Ao contrário do proposto pelo primeiro grupo de especialistas que a pensaram, os membros do Ecosoc preferiram que a $\mathrm{CDH}$ fosse um órgão intergovernamental, e não uma agência com funcionários independentes. Seus membros eram, portanto, representantes de Estados. Por sua vez, os membros da Subcomissão atuavam em suas capacidades pessoais, ou seja, oficialmente não eram representantes estatais. Entretanto, dificilmente operavam em descompasso com seus Estados de origem, uma vez que sua eleição dependia da aquiescência daquele Estado. Como veremos abaixo, nem sempre a atuação na capacidade pessoal significava que o membro da Subcomissão não articulasse seus posicionamentos com seus países de origem; pelo contrário,

\footnotetext{
3 Todavia, a CDH não teve participação em outros documentos importantes dessa mesma época, como a Convenção sobre Genocídio de 1948, a Convenção para a Repressão do Tráfico de Pessoas de 1950 e os documentos sobre direitos das mulheres, redigidos pela Comissão sobre o Status da Mulher.

4 Na criação da CDH, o Ecosoc sugeriu a criação da Subcomissão sobre Liberdade de Informação e de Imprensa, da Subcomissão para a Proteção de Minorias e da Subcomissão para a Prevenção da Discriminação. As duas últimas foram unificadas na Subcomissão de Prevenção da Discriminação e Proteção de Minorias e a primeira foi extinta pelo Ecosoc em 1952.
} 
quando os diplomatas brasileiros pressionavam, os membros da Subcomissão sempre procuravam as delegações dos seus países de origem, às vezes com sucesso e outras vezes não.

Inicialmente, os membros da $\mathrm{CDH}$ decidiram que o órgão não receberia denúncias de violações de direitos humanos. "A Comissão reconhece que não tem poder para tomar qualquer medida a respeito de reclamações concernentes aos direitos humanos" (United Nations, 1947, paras. 21-2) foi o texto de sua primeira sessão, um posicionamento referendado pelo Ecosoc. Tal decisão não passou ilesa à época. O internacionalista Hersch Lauterpacht foi um dos que se opuseram a tal desenho. Receber, examinar e agir a partir das denúncias de violações seria um dos propósitos da própria ONU, em sua opinião. A abdicação da Comissão ia contra sua razão de ser (Lauterpacht, 1950). Mas quais eram as razões dessa escolha institucional? De acordo com analistas, não havia uma maioria de Estados interessados nessa configuração (Alston, 1992; Belli, 2009; Lindgren Alves, 1994; Tolley, 1987). Países como os Estados Unidos receavam casos envolvendo discriminação racial. Outros, como Reino Unido, Portugal, França e Bélgica, temiam denúncias sobre suas colônias. Países socialistas temiam pretextos intervencionistas e se acastelavam no artigo $2^{\circ}, \S^{\circ}$, da Carta. Assim, falharam as iniciativas de implementação de um sistema de petição propostas por países como Egito, Índia e Filipinas (Alston, 1992). Ainda não havia textos legais vinculantes para respaldar denúncias (Tolley, 1987).

A transformação da CDH em uma instituição que recebia denúncias começou a ser aventada quando novas vontades políticas surgiram. O ingresso dos recém-descolonizados da África e da Ásia alterou a ONU de forma significativa, suas narrativas, desenho institucional e agenda política (Jensen, 2016). Algumas experiências no sistema onusiano rascunharam procedimentos de petições e 
comunicações individuais, ${ }^{5}$ e seu aprendizado influenciou o que se pretendeu com a $\mathrm{CDH}$. Os recém-independentes africanos e asiáticos foram os responsáveis por avançar novos enquadramentos sobre direitos humanos (Mutua, 2002), além de uma reformulação na CDH. Impulsionados pelas condenações ao regime do apartheid e à experiência colonial, e sob influência do Comitê da Descolonização, esses países conseguiram que o Ecosoc recomendasse à $\mathrm{CDH}$ ação urgente em casos de violações de direitos humanos, incluindo políticas de discriminação, segregação racial e de apartheid, com destaque para violações ocorridas em países e territórios colonizados ou dependentes (United Nations, 1966a). A restrição geográfica logo foi repensada e, para que a atenção da $\mathrm{CDH}$ não ficasse restringida, a Assembleia Geral da ONU aprovou a resolução 2144 A (XXI) (United Nations, 1966b) que direcionava a CDH a "quaisquer lugares que [as violações] ocorram".

$\mathrm{O}$ Ecosoc adotou duas resoluções que direcionaram os trabalhos da $\mathrm{CDH}$ e que criaram dois sistemas de análise de denúncias. Primeiro, a resolução 1235 (XLII) de 1967 do Ecosoc permitiu à CDH conduzir um debate público anual sobre as situações. A CDH e a Subcomissão passaram a ter competência para "examinar as informações pertinentes a violações graves dos direitos humanos e liberdades fundamentais em todos os países", podendo a $\mathrm{CDH}$ "realizar estudo aprofundado das situações que revelem um padrão sistemático de violações de direitos humanos [...] e relatá-lo, com recomendações, ao Conselho" (Ecosoc, 1967). ${ }^{6}$ Em 1967,

\footnotetext{
${ }^{5}$ O artigo 14 da Convenção Internacional sobre a Eliminação de Todas as Formas de Racismo (1965) e o Protocolo Facultativo ao Pacto Internacional sobre Direitos Civis e Políticos (1966) criaram mecanismos de submissão de denúncias feitas por indivíduos ou grupos contra Estados.

${ }^{6}$ Os grupos de peritos tinham a atribuição de coletar dados e realizar análises, mas os países investigados não lhes permitiam a visita em seus territórios (a única exceção foi o governo chileno, que aprovou uma visita em 1978 e depois outras a partir de 1985), o que limitou muito seus trabalhos.
} 
a CDH criou um grupo especial para a África Austral (África do Sul, e depois ampliado para Namíbia, Rodésia do Sul e colônias portuguesas da África) e, em 1969, para os territórios árabes ocupados por Israel. Foi um período em que países africanos e asiáticos conseguiram avançar suas pautas em enquadramentos distintos dos pretendidos por ocidentais, inclusive sobre direitos humanos (Mutua, 2002).

Em maio de 1970, a resolução 1503 do Ecosoc estabeleceu o segundo sistema. Se o primeiro instituiu um "controle ostensivo", o segundo era de "controle confidencial", uma vez que o teor das denúncias não era divulgado. A resolução 1503 autorizou a Subcomissão a criar um grupo de trabalho de não mais do que cinco membros para considerar comunicações, bem como as respostas dos governos, para verificar um possível "padrão consistente de violações flagrantes e seguramente comprovadas de direitos humanos e liberdades fundamentais" (Ecosoc, 1970). Sua intenção era considerar situações de violações e usava as denúncias como fontes de informação, mas não analisava demandas individuais como as cortes regionais de direitos humanos. Ainda assim, o sistema criado pela resolução 1503 tinha muita demanda. O caso contra a ditadura brasileira foi analisado por meio dele, em um momento em que seus trâmites burocráticos eram definidos. ${ }^{7}$

\footnotetext{
7 A resolução 1503 estabeleceu que os membros do grupo de trabalho, em reuniões privadas, deveriam decidir as informações por maioria simples, remeter novamente o caso à Subcomissão que, por sua vez, poderia enviá-lo ao plenário da Comissão (Ecosoc, 1970). Em agosto de 1971, a Subcomissão adotou a resolução 1, na qual estabeleceu os critérios de admissibilidade de denúncias (Sub-commission..., 1971). Os procedimentos só começaram a ser aplicados em 1972. O Secretariado recebia a denúncia, repassava à CDH e comunicava ao Estado acusado. A primeira apreciação da denúncia era feita pelo grupo de trabalho sobre comunicações, designado pela Subcomissão, que também considerava as possíveis respostas dos Estados. Após consideração, o grupo, que se reunia por cerca de dez dias em Genebra, redigia um relatório para a Subcomissão. Por sua vez, a Subcomissão, que se reunia uma vez por ano, decidia em sessão confidencial se era pertinente ou não levar as comunicações à $\mathrm{CDH}$, reenviar para o grupo de trabalho ou mesmo postergar sua decisão. Era na transmissão para a CDH que uma denúncia deixava de ser uma "comunicação" para se tornar uma "situação". Quando decidia transmitir uma situação para a CDH, a Subcomissão enviava um relatório confidencial.
} 


\section{Os casos contra a ditadura vão para a ONU}

Ainda que acusações de violações contra a ditadura brasileira já acompanhassem o regime desde o golpe, sua circulação no plano internacional intensificou-se no final dos anos 1960, principalmente após o AI-5 (Brasil, 2014; Green, 2009). O golpe e o novo governo que se instalou impactaram as práticas institucionais do Itamaraty, que passou a ter que defender o regime no plano internacional (Batista, 2010; Carmo, 2018). Após dez anos de regime militar, com a chegada de Ernesto Geisel ao poder, ao lado de Golbery do Couto e Silva, o processo conhecido como "abertura" significou oscilações de medidas de repressão e de apaziguamento. Seu projeto de distensão impactou toda sua gestão, inclusive sua política externa (Spektor, 2004). Na opinião de um historiador, longe de um processo altruísta, a distensão fez parte da institucionalização pretendida, com controle maior da condução política ao mesmo tempo em que não

112 se interrompia o aparelho repressivo (Napolitano, 2014). Se o MDB ganhava mais espaço e apoio popular, medidas legislativas como a Lei Falcão e o Pacote de Abril garantiam o controle de Geisel. A repressão não cessou neste processo: com exceção do governo Médici, os dois primeiros anos da administração Geisel têm o maior número de denúncias de tortura (Gaspari, 2014), e no primeiro ano do seu governo "foram registrados 54 desaparecimentos políticos, o maior número do regime" (Brasil, 2014, p. 104).

A linguagem dos direitos humanos se apresentava como uma ameaça aos propósitos da distensão. Por um lado, a esquerda demandava um retorno mais célere à democracia, liberdade aos presos políticos e fim das torturas; por outro, a extrema direita, como o ministro do exército Sylvio Frota, se opunha à distensão e defendia as medidas de repressão contra "subversivos". Direitos humanos era um vocabulário que poderia municiar a oposição a Geisel tanto pela esquerda, enquadrando suas demandas, quanto pela 
direita, confirmando que o governo recuava dos propósitos originais do regime. Assim, casos contra o país em instâncias internacionais poderiam atrapalhar o controle do processo político que a administração Geisel arquitetava.

Mesmo antes de Geisel chegar ao poder, comunicações sobre violações de direitos humanos cometidas durante o período ditatorial chegaram à Comissão pelo menos desde 1969, de acordo com a resolução 728 (XXVIII) do Ecosoc, por meio de organizações domésticas como o Comitê de Solidariedade a Presos Políticos de Belo Horizonte (MRE, 1969) e estrangeiras, como a Federação Sindical Mundial, a Organização Internacional de Jornalistas, a Federação Democrática das Mulheres e a Comissão Internacional de Juristas. Ativistas e organizações da sociedade civil pressionavam o sistema ONU para que esse se ocupasse de denúncias, e a recém-adotada resolução 1503 lhes deu esperanças. A Subcomissão calculou que recebeu 20.000 denúncias só em 1971 (United Nations, 1972), uma estimativa conservadora para Tardu (1980). Tolley (1987) calculou que a Subcomissão recebeu 35.000 denúncias nos três primeiros anos de funcionamento. No entanto, poucas denúncias viravam "situações": entre 1973 e 1979, a Subcomissão remeteu para a Comissão apenas 20 situações (Tolley, 1987).$^{8}$

Das várias denúncias feitas contra a ditadura brasileira, destaca-se o relatório da Anistia Internacional. ${ }^{9}$ A ONG iniciou sua atuação no Brasil a partir de 1966 e continuou listando casos individuais de tortura e presos políticos no país nos anos seguintes (Vreche, 2017). Publicado no Dia

\footnotetext{
8 Seriam elas: seis da África (Burundi, Guiné Equatorial, Etiópia, Malaui, Tanzânia, Uganda), seis da Ásia (Mianmar, Indonésia, Irã, Israel, Coréia, Vietnã do Sul), seis da América Latina (Bolívia, Brasil, Chile, Guiana, Paraguai e Uruguai) e duas da Europa Ocidental (Portugal e Reino Unido) (Tolley, 1987).

9 De acordo com os documentos confidenciais e secretos nos arquivos do MRE, o relatório da Anistia de 1972 foi o principal documento contra a ditadura a ser enviado para a ONU. Foi seguramente o que mais mobilizou as energias da diplomacia do regime militar para seu arquivamento e esquecimento.
} 
da Independência do Brasil de 1972, o Report on Allegations of Torture in Brazil (doravante "relatório") refere-se a eventos de 13 de dezembro de 1968 a 15 de julho de 1972. Como os membros da Anistia foram impedidos de entrar no país, o documento teve como fonte informações que circulavam internacionalmente. Desde o final dos anos 1960, durante os "anos de chumbo", redes transnacionais de exilados, ativistas e simpatizantes se organizavam no exterior para documentar e publicizar violações de direitos humanos da ditadura (Green, 2009; Marques, 2011; Vreche, 2017).

O relatório começa detalhando a legislação desde o início do golpe, com ênfase nas medidas de segurança nacional e os atos institucionais, a criação de agências e órgãos de segurança, banimentos, julgamentos políticos, dentre outros. Após a descrição institucional dos rumos autoritários do regime, foram expostas suas consequências: choques elétricos, abusos sexuais, pau de arara e espancamentos são 114 apresentados ao lado de nomes de pessoas que sofreram a sevícia. São essas pessoas quem falam e nelas reside a força do texto: seus relatos têm seus afetos, sentidos, palavras, lugares e nomes, têm, enfim, a sua narrativa, algo que não circulava no Brasil em tempos de autoritarismo. Sua forma e estética transmitem uma sensação de descrição de eventos com riqueza de detalhes que fortalece sua veracidade. Seus números são expressivos: 1.081 vítimas e 472 perpetradores de violações vinculados a organizações diversas, como a Oban, Codi, Dops, Cenimar e polícia militar (Amnesty International, 1972a). ${ }^{10}$

A publicidade era tanto estratégia quanto objetivo de ativistas e ONGs de direitos humanos como a Anistia. O governo brasileiro respondeu proibindo a entrada de ONGs e ativistas no país, além de banir menções à Anistia na imprensa

${ }_{10}$ A lista de perpetradores era confidencial e foi enviada apenas para o governo brasileiro e para organizações internacionais. Ainda assim, em alguns trechos do relatório constam nomes de agentes do regime, como o delegado Sérgio Fleury. 
nacional. Antes do banimento, reportagens chegaram a associar a Anistia a um "instrumento do terrorismo comunista" interessado em uma campanha para "agitar a opinião pública contra as autoridades brasileiras" (Amnesty International, 1972b, p. 2). A Anistia tentou dar a maior publicidade possível e o relatório circulou clandestinamente no Brasil, foi enviado à $\mathrm{CDH}$, OEA e representações diplomáticas de diversos países. De acordo com relatos colhidos por James Green (2009), seu acompanhamento de perto e suas campanhas resultaram na libertação de presos específicos, como Teodoro Ghercov e Ivan Akselrud de Seixas. De qualquer forma, suas conclusões não se restringiam a casos específicos.

Quando considerou as funções da tortura, o relatório entendeu-a não só como instrumento policial e de repressão, mas também como "se tornou um instrumento de poder sob a direção governamental”, uma forma de "intimidação para controlar os pensamentos e vontades das pessoas" (Amnesty International, 1972a, p. 64). A tortura não era exceção e acidental ao regime, mas um dos seus elementos constitutivos.

\section{As estratégias iniciais da diplomacia da ditadura}

O governo brasileiro foi informado do envio do documento da Anistia para a ONU desde o início. Nos arquivos do MRE, há vários documentos que revelam a troca de informações com os participantes da Subcomissão (que supostamente atuariam a título pessoal). Em setembro de 1973, o membro da Subcomissão Héctor Gros Espiell (futuro juiz da Corte Interamericana de Direitos Humanos e chanceler uruguaio) alertou Ramiro Saraiva Guerreiro, então chefe da representação brasileira em Genebra, que três dos quatro partícipes do grupo de trabalho concordavam que o caso contra o Brasil deveria seguir adiante para a Subcomissão. $\mathrm{Na}$ avaliação de Gros Espiell, na Subcomissão, mesmo que os latino-americanos votassem contra o seguimento do caso, eles provavelmente perderiam. Todavia, o cenário 
desfavorável ao regime militar era compensado pelo ineditismo das ações da CDH e o que se poderia fazer frente às denúncias. Os poderes da resolução 1503 de 1970 ainda não estavam claros. "Como se sabe", avaliou Saraiva Guerreiro, "a Comissão dos Direitos do Homem [sic] nunca teve reconhecida a sua competência para examinar casos concretos de violação por parte de Estados-membros, embora sempre houvesse uma campanha para atribuir-lhe tais poderes" (MRE, 1973).

A ONU apresentou formalmente ao Brasil a denúncia feita pela Anistia em fevereiro de 1974. O caso seria analisado na $30^{\underline{a}}$ Sessão da $\mathrm{CDH}$, quando ONGs acreditadas, como a própria Anistia, poderiam se manifestar. $\mathrm{O}$ representante brasileiro em Genebra ainda titubeava sobre a melhor forma de agir, pois o país ainda não tinha se manifestado formalmente e receava que o texto da Anistia se tornasse a única referência no debate. A resposta de Brasília veio 116 poucos dias depois. As instruções enviadas pela Secretaria Geral do MRE, em fevereiro de 1974, estabeleceram pela primeira vez uma forma mais sistemática de ação em relação ao sistema onusiano de direitos humanos. A estratégia imediata foi desqualificar o documento, apontando suas "motivações políticas" e que sua leitura da "doutrina de segurança nacional" era "pouco honesta, parcial, e politicamente orientada". As instruções asseveraram ainda que não se poderia aceitar um "julgamento" do país e que a "fase de estabilidade, e de progresso político, econômico e social" que o país atravessava habilitava-o a examinar domesticamente as denúncias. Por fim, assegurou que as denúncias seriam encaminhadas aos órgãos brasileiros (MRE, 1974a).

A diplomacia brasileira tirava proveito da hesitação onusiana sobre questões processuais. Os próprios membros da CDH vacilavam sobre quais procedimentos adotar dada a ausência de precedente de aplicação da resolução 1503. Era a primeira vez que casos eram ouvidos. A CDH analisava 
várias demandas e o momento de definição era importante. ${ }^{11}$ Em março de 1974, os membros da $\mathrm{CDH}$ decidiram adiar a apreciação do caso brasileiro e remeteram-no a um novo grupo de trabalho que apresentaria outro relatório no ano seguinte.

Geisel inaugurou sua presidência em março de 1974 e Azeredo da Silveira assumiu o cargo máximo no MRE. A política externa do período ganhou novos contornos e conectava-se com o processo de distensão política (Spektor, 2004). Como mencionado, o dossiê elaborado pela Anistia poderia ser problemático aos seus propósitos. Enquanto os trâmites burocráticos na ONU ainda titubeavam, a ditadura ganhava tempo e uma atuação diplomática mais delineada. O processo decisório foi mais centralizado e não raro os documentos passavam pela alta cúpula. A $\mathrm{CDH}$, a Subcomissão e o grupo de trabalho começaram a ser observados regularmente e os diplomatas brasileiros identificavam quais pessoas e delegações tinham mais abertura às demandas do país. Pedidos de outras delegações começaram a depender de apoio ao arquivamento do caso. ${ }^{12} \mathrm{O}$ assunto passou a ser abordado não apenas em Genebra e Nova York: nas tratativas de Ramiro Saraiva Guerreiro, agora Secretário Geral do MRE, com o embaixador soviético em Brasília, o representante brasileiro reclamou do comportamento daquele país na Subcomissão e lembrou que a URSS também era alvo da Anistia (MRE, 1974e). A questão também foi interpelada por meio de nota ao Secretário Geral e aos membros da Subcomissão, o governo brasileiro manifestou

11 Poucos dias antes da discussão do caso brasileiro na $\mathrm{CDH}$, uma reportagem do New York Post sugeria uma articulação contra o Brasil por parte de países ocidentais. Diplomatas brasileiros procuraram seus colegas dos Países Baixos, Reino Unido, Noruega, EUA e França. Um representante britânico insinuou que a notícia do jornal poderia ter sido plantada pela Anistia (MRE, 1974c).

12 Quando o governo dinamarquês pediu apoio a uma vaga nas eleições de membros da CDH, por exemplo, a delegação brasileira cobrou um posicionamento mais positivo em relação ao país (MRE, 1974d). 
sua preocupação com as condições de admissibilidade das comunicações, mas se mostrou disposto a cooperar.

A política externa da administração Geisel e Silveira lidou de forma mais esquemática com o tema dos direitos humanos. Em agosto de 1974, foi formado um Grupo Interministerial com representantes do Ministério da Justiça, do Serviço Nacional de Informações, do Conselho de Segurança Nacional e de várias áreas do MRE. Coordenado pelo MRE na figura do diplomata João Clemente Baena Soares, o grupo tinha a função de "examinar o tratamento de questões relativas aos direitos humanos, de interesse direto para o Brasil, no âmbito da ONU e da OEA". Na sua primeira reunião, agrupou em três as principais alegações contra o país: genocídio ou tratamento desumano de indígenas, injustiça social e desigualdade da distribuição da renda nacional e repressão, tortura ou eliminação dos adversários políticos. Especificamente sobre a $\mathrm{CDH}$, 118 o Grupo Interministerial indicou a necessidade de abertura de diálogo e pediu o ingresso do país no órgão onusiano (MRE, 1974a). O posicionamento de cooperar ou não com a CDH (assim como com a OEA) ainda não era consensual. Segundo documentos analisados pela Comissão Nacional da Verdade, a consultoria jurídica e a Divisão de Segurança e Informações do Ministério da Justiça entendiam que o governo não deveria responder às acusações. Em uma nota manuscrita, o Ministro da Justiça, Armando Falcão, indicou que a orientação vinha de cima: o presidente Geisel tinha decidido que se deveria responder a tais organizações (Brasil, 2014).

Enquanto isso, outros documentos contra o Brasil chegavam à CDH. Em agosto de 1974, a Subcomissão analisou novas denúncias. O uruguaio Gros Espiell propôs seu arquivamento e foi apoiado pelos membros do Equador, Chile e URSS. O estadunidense Beverly Carter foi contra e a ele se juntaram os integrantes do México, 
Marrocos e Filipinas. A solução proposta pelo equatoriano Martinez Cobo foi "de compromisso": suprimir a menção ao Brasil no relatório, mas remeter documentação para a CDH para anexá-la ao dossiê existente. O governo brasileiro não deixou de demonstrar sua insatisfação junto às delegações daqueles que votaram contra o país, mesmo que os membros da Subcomissão não representassem seus países. Quando questionou sobre a postura de Beverly Carter, a delegação estadunidense respondeu que ele atuava a título pessoal e que não representava Washington (MRE, 1974f).

Apesar da continuidade do caso, as estratégias brasileiras renderam bons resultados. O embaixador Sergio Armando Frazão escreveu para Brasília que a imagem que o Brasil passava na Subcomissão era de "afirmação e interesse”, ao contrário de outros países, como o Chile. Frazão mencionou ainda o apoio do integrante da Subcomissão, Martinez Cobo, que elogiou o desenvolvimento econômico brasileiro, a situação indígena e a receptividade das autoridades quando da viagem ao país. Contudo, na análise de Frazão, o que ele chamava de "politização" da CDH vinha aumentando e ele aconselhou que o governo brasileiro se candidatasse a uma das vagas da CDH nas eleições de 1975, o que "dificultaria ou impediria o tipo de colocações negativas que vêm ocorrendo" (MRE, 1974g).

\section{A intensificação das atividades diplomáticas e o arquivamento do caso}

Em 1975, quando a 31 ํㅗ sessão da CDH se avizinhava, a diplomacia brasileira trabalhava com dois cenários: arquivamento do dossiê ou adiamento da decisão. Para isso, a articulação com outros países tinha que ser eficiente e rápida e os documentos do arquivo do MRE mostram como a diplomacia da ditadura atuou de forma coordenada em três fronts: Brasília, Nova York e 
Genebra. Grande parte das "gestões" bilaterais aconteceu em Genebra. ${ }^{13}$ Saraiva Guerreiro instruiu o embaixador George Álvares Maciel para concentrar esforços junto aos membros do grupo de trabalho (Gana, Países Baixos, Paquistão e Panamá, sendo que o quinto membro não chegou a ser eleito), e às delegações desses países. Maciel deveria reiterar que as denúncias estavam sendo verificadas no plano doméstico (MRE, 1975b).

O grupo de trabalho relutava em arquivar o caso contra o Brasil, mas cedeu em relação ao seu adiamento. Sua recomendação, seguida pela Subcomissão, foi que se "estudasse em profundidade o assunto, levando em consideração as observações que o governo brasileiro pretende apresentar a respeito" (MRE, 1975d). Quando da sua apreciação na $31^{\underline{a}}$ sessão, o representante brasileiro interveio e alertou a $\mathrm{CDH}$ para que não tomasse uma decisão precipitada, levantando os mesmos argumentos formulados em Brasília.

120 A defesa brasileira coube ao diplomata Luiz Henrique Pereira da Fonseca que apresentou uma série de justificativas para a demora no esclarecimento das denúncias, como volume de documentos, fatos ocorridos em regiões remotas e, há tempos, processos burocráticos lentos nas etapas administrativas e judiciais (Brasil, 2014). Ao explicar ao Ministro da Justiça o resultado dessa etapa, o chanceler Azeredo da Silveira concluiu: "O exame da questão foi encaminhado segundo o interesse brasileiro, visto que a $\mathrm{CDH}$ ratificou a conclusão do GT, especificando que a 32 ${ }^{\underline{a}}$ Sessão, a realizar-se em 1976, deverá estudar mais a fundo a situação, levando em conta as observações que o governo brasileiro deseje comunicar à CDH” (MRE, 1975d). Novamente, a ditadura militar se beneficiava com o adiamento da decisão.

\footnotetext{
13 Em um caso, um diplomata panamenho manifestou pronto e decidido apoio associado à possibilidade de uma vaga em um curso de medicina em uma faculdade brasileira para um estudante, a pedido do próprio General Omar Torrijos, chefe do governo daquele país (MRE, 1975c).
} 
Enquanto isso, novos casos contra o Brasil continuavam chegando na CDH. Os arquivos da CDH reúnem documentos variados: de denúncias bem documentadas de organizações, como a Federação Sindical Mundial e a Federação Democrática Internacional de Mulheres, a cartas de congressistas dos EUA, do Partido Comunista da Jamaica e de cidadãos de vários países que se diziam alarmados com a situação geral de direitos humanos no país. O regime militar se preocupava com essas novas denúncias e o Grupo Interministerial arregimentou informações sobre algumas. A diplomacia da ditadura procurava evitar que novas denúncias fossem juntadas ao dossiê preparado pela Anistia. Em agosto de 1975, o representante nicaraguense informou Maciel que todas as novas comunicações contra o Brasil foram desconsideradas (MRE, 1975e). Nos arquivos consultados do MRE, não há maiores detalhes sobre as razões do grupo de trabalho e se o arquivamento foi resultado da pressão exercida pela diplomacia brasileira.

No ano de 1975, o Grupo Interministerial se reuniu pelo menos três vezes para lidar com os casos contra a ditadura na ONU. Seu processo decisório chegou ao mais alto nível da burocracia estatal e suas conclusões foram aprovadas pelo próprio presidente Geisel. Saraiva Guerreiro enviou as diretrizes para Genebra: (1) é conveniente apresentar uma resposta, "desde que tal iniciativa não implique o reconhecimento de necessidade de defesa, mas demonstre a importância que conferimos à manutenção do diálogo com a comissão"; (2) a resposta deve ser de caráter político e tom genérico, não buscando a refutação de cada caso, mas sim a explicitação da posição do governo brasileiro de defesa dos direitos humanos no país (MRE, 1976b).

Ao mesmo tempo em que o governo brasileiro se engajava com a Comissão, reconhecendo sua importância e trabalho, entrincheirava-se no entendimento de que não se tratava de um julgamento. A diplomacia da ditadura consolidava 
a impressão de que o país até poderia cooperar em prol dos direitos humanos, mas o fazia não como cumprimento de normas ou porque era obrigado, mas porquanto tinha vontade soberana para tal. O entendimento de direitos humanos defendido pela ditadura era que eles se realizavam pelo e dentro do Estado e que seu arranjo na ONU era submetido à noção de soberania - um enquadramento que passou a ser questionado no decorrer dos anos 1970 (Roriz, 2017).

Em janeiro de 1976, poucos dias antes da 32ª Sessão da $\mathrm{CDH}$, o regime militar apresentou sua resposta formal. Os argumentos listavam uma série de normas, instituições e supostas garantias legais vigentes do país. O espírito legalista que a ditadura tanto nutriu (Pereira, 2010) também podia ser observado na diplomacia. $\mathrm{O}$ governo não se escusou de mencionar um documento capaz de "suspender certas garantias e direitos constitucionais" - o infame AI-5 - e o justificou frente às "tentativas de guerra revolucionária em 122 finais da década passada" e ressaltou que foi "acolhido na Constituição”. Relatou que o país vinha experimentando "grande transformação no plano econômico, social e político" e que promoveu uma reforma agrária. Por fim, concluiu que o "governo brasileiro se dispôs a estes comentários ainda que ligados a assuntos de natureza interna e de sua competência exclusiva, animado tão somente do melhor espírito de cooperação internacional” (MRE, 1976c).

As "gestões" continuaram junto aos participantes do grupo de trabalho e suas delegações, Paquistão, Iugoslávia, Panamá, França e Tanzânia. Àqueles menos afeitos aos argumentos formais brasileiros, a delegação brasileira em Genebra recebeu instruções para usar um documento preparado pelo SNI que detalhava os "atos criminosos" das pessoas mencionadas no dossiê contra o Brasil. Para que não fosse confundida com sua resposta formal de não apresentar detalhes sobre cada uma das alegações, a delegação brasileira em Genebra deveria mostrar os documentos "para 
ilustrar o caráter geral tipicamente criminoso e subversivo", com o cuidado de não entregá-los formalmente à $\mathrm{CDH}$ (MRE, 1976d). Em relação à delegação iugoslava, foi ressaltado: "Como seu interlocutor é de orientação marxista, em seu contato acentuará a natureza violenta e criminosa dos atos praticados e omitirá qualquer referência à motivação ideológica que pode havê-los inspirado" (MRE, 1976e).

Os telegramas diplomáticos mostram a ansiedade de Brasília. As instruções ao delegado brasileiro eram enfáticas: ele deveria "envidar os máximos esforços" para arquivamento do dossiê. No grupo de trabalho, as posições divergiam. Na avaliação do diplomata, a França era "francamente condenatória" ao Brasil, a Iugoslávia, "moderadamente condenatória”, a Tanzânia "inconsistente”, e o Paquistão mostrava seu "apoio irrestrito" ao país (MRE, 1976e). ${ }^{14}$

Nos dias seguintes, a delegação brasileira intensificou o diálogo com os membros do grupo, principalmente com o iugoslavo (MRE, 1976g). Se as posições iniciais divergiam, no momento da redação do relatório, a ditadura foi favorecida. O relatório do grupo de trabalho entendeu que a resolução 1503 se tornou aplicável a partir de 27 de maio de 1970 para situações que ocorreram posteriormente, o que prejudicou as denúncias que antecediam a data. $\mathrm{O}$ grupo assumiu que não conseguiu verificar se as alegações tinham fundamento ou não, e que o governo brasileiro "tem os meios necessários para prevenir violações de direitos humanos" na forma dos seus instrumentos jurídicos. Foi afirmado, ainda, que desde a $31^{\underline{a}}$ Sessão da $\mathrm{CDH}$, nenhuma nova comunicação foi transmitida pela Subcomissão - uma confirmação dos esforços brasileiros em barrar novas denúncias. O grupo de trabalho concluiu que não havia ações necessárias em relação à resolução 1503 (MRE, 1976h) e o seu relatório foi enviado ao plenário da $\mathrm{CDH}$.

${ }^{14} \mathrm{O}$ membro do Panamá não compareceu à reunião. 
Na prática, a redação do grupo de trabalho significava o arquivamento do dossiê e coroava a empreitada diplomática da ditadura.

A atividade da diplomacia brasileira na $32^{\underline{a}}$ Sessão da $\mathrm{CDH}$ continuou intensa. O representante brasileiro Amaury Bier mostrava-se confiante: "As conclusões do GT de Comunicações, reforçadas pelas extensas gestões realizadas em Brasília, Genebra, Nova York e nas capitais dos países interessados, criaram um quadro parlamentar em que é virtualmente impossível imaginar qualquer tipo de condenação ao Brasil”. Em telegrama para Brasília direcionado ao ministro Baena Soares, Bier chegou a considerar que a votação poderia ser unânime em favor do Brasil. O Brasil poderia ter "novas bases de cordialidade e respeito" com a $\mathrm{CDH}$, findada a questão do dossiê (MRE, 1976i).

Ainda que a votação não tenha sido unânime, a confiança do diplomata brasileiro se mostrou fundamentada. O relatório do grupo de trabalho foi usado como referência durante as discussões. No dia 3 de março de 1976, na 32ª Sessão da $\mathrm{CDH}$, o dossiê contra o Brasil foi arquivado por dezesseis votos a favor, três contra e seis abstenções. ${ }^{15}$ Como provavelmente um último esforço para salvar o dossiê, o representante dos EUA, Leonard Garment, chegou a propor uma comissão de investigação contra o Brasil, o que não recebeu apoio (MRE, 1976j). Lindgren Alves (1994) destaca o posicionamento decisivo da Iugoslávia em conjunto com a proposta uruguaia para arquivamento do caso na Comissão. Mesmo com tais apoios, não há como ignorar os sucessos da movimentação diplomática brasileira. A cada etapa do longo trâmite burocrático, o Brasil angariou apoio, ganhou votos e usou a burocracia a seu favor.

15 O Brasil foi apoiado por Egito, Líbia, Ruanda, Serra Leoa, Tanzânia, Alto Volta, Chipre, Índia, Irã, Jordânia, Líbano, Paquistão, Costa Rica, Equador, Panamá, Peru, Uruguai, Turquia e Nigéria. Votaram contra: Áustria, Canadá e Estados Unidos. Abstiveram-se na votação: Cuba, França, Rep. Federal da Alemanha, Lesoto, Itália e Irlanda. 


\section{De acusado a membro da Comissão de Direitos Humanos}

$\mathrm{O}$ arquivamento do dossiê contra o Brasil não significou um relaxamento da política externa de direitos humanos da ditadura. Poucos meses depois, a Anistia Internacional apresentou um novo dossiê contra o regime. Na informação para o presidente Geisel, o chanceler Silveira avaliou que o documento seria uma ameaça ainda maior. A questão cronológica foi ajustada pela Anistia: as denúncias eram todas posteriores a janeiro de 1975, o que eliminaria o óbice temporal no entendimento da $\mathrm{CDH}$. Sobre seu conteúdo, Silveira avaliou: "muito embora o novo dossiê não seja numericamente tão expressivo quanto o anterior (cerca de 1.300 alegações, no primeiro, contra pouco mais de uma centena, no atual), a circunstância de que a nova documentação cobre prazo mais exíguo e se apresente em forma bastante estruturada é prejudicial” (MRE, 1976k). Um número menor de violações e mais limitado no tempo dificultaria o argumento antes usado de que não haveria como averiguar todas as denúncias. Além da questão temporal e do conteúdo, Silveira avaliou que havia ainda outros agravantes. Primeiro, os direitos humanos não tinham esmorecido no contexto internacional, pelo contrário, o tema ganhou destaque. Segundo, a composição da CDH tornou-se mais adversa ao Brasil com a eleição da Áustria e Suécia, além dos latino-americanos terem ainda uma presença modesta. Por fim, segundo Silveira, o Brasil dependeria da articulação com os africanos, asiáticos e árabes. Diante desse quadro, o chanceler acionou novamente o Grupo Interministerial, a fim de avaliar o conteúdo da nova denúncia (MRE, 1976k).

A análise de conjuntura de Silveira tem acertos e erros. Ele foi preciso em sua leitura sobre a importância crescente do tema dos direitos humanos no plano internacional. No ano seguinte, Jimmy Carter foi eleito presidente dos EUA e alçou o tema dos direitos humanos ao âmago da sua política externa. Ainda em 1977, a Anistia Internacional 
recebeu o Prêmio Nobel da Paz justamente por sua atuação na área. Um novo enquadramento sobre o assunto colidia com aquele antes contido no discurso de soberania (Roriz, 2017). Por outro lado, a avaliação de Silveira sobre o perigo do novo dossiê não se concretizou. Ao contrário do que aconteceu com o dossiê apresentado pela Anistia em 1972, o novo não foi longevo nem custoso à ditadura. Há poucas informações nos arquivos sobre os detalhes do seu trâmite, mas ele não durou mais do que alguns meses e foi arquivado na primeira instância do processo da $\mathrm{CDH}$. Um documento de 1977 menciona seu fim logo na reunião seguinte da Subcomissão graças aos membros do Paquistão, Gana e Nicarágua (MRE, 1977a), sugerindo que a composição da Subcomissão foi essencial.

Os documentos da $33^{\text {a }}$ Sessão da $\mathrm{CDH}$, realizada em 1977, não mencionam nenhum caso contra o regime militar brasileiro. Brasília, ainda assim, continuava de guarda.

126 As instruções para a delegação brasileira indicavam que caso a delegação estadunidense ou um representante de ONG mencionasse o Brasil, dever-se-ia "invocar direito de resposta” (MRE, 1977b). ${ }^{16}$ Todavia, a ditadura brasileira não foi alvo de críticas substantivas e os únicos latino-americanos mencionados foram Argentina, Chile e Uruguai.

Não poderia ter sido mais oportuno para o Brasil o momento em que o país saiu do radar da CDH. Após a 33ํㅗㅡ Sessão, o representante brasileiro em Genebra, George Álvares Maciel, destacou a expectativa gerada pela administração Carter e a centralização dos direitos humanos na sua política externa. Dentre os resultados da militância

\footnotetext{
${ }^{16} \mathrm{Na}$ (eventual) réplica, o diplomata brasileiro deveria ressaltar que o país não está na agenda da Comissão, que mantém um "diálogo construtivo" e que o órgão onusiano não poderia se tornar "um palco para espetáculos de valor publicitário". Deveria mencionar ainda que o sentimento majoritário dos membros seria maior que "vozes isoladas que buscam evidentemente tumultuar o convívio internacional e utilizar os valores objetivos da cooperação internacional para promoção dos direitos humanos para fins espúrios" (MRE, 1977b).
} 
estadunidense, na opinião do diplomata brasileiro, estariam o crescente foco em alguns casos como África do Sul, URSS, Uganda, Argentina, Uruguai e Paraguai, além da transformação da CDH em um "tribunal em que vítimas iam depor". A diplomacia dos EUA conseguia dar mais publicidade aos casos e auxiliava ONGs, que se tornavam "mais militantes e agressivas", na leitura de Maciel (MRE, 1977b).

Nos meses seguintes à 33-a Sessão da $\mathrm{CDH}$, o regime militar resolveu se candidatar a uma vaga como membro da Comissão de Direitos Humanos da ONU. A sugestão já tinha sido feita por Sergio Armando Frazão em 1974: o Brasil como membro da $\mathrm{CDH}$ "dificultaria ou impediria o tipo de colocações negativas que vêm ocorrendo" (MRE, 1974g). Em 1975, o Grupo Interministerial também aconselhou que o Brasil ingressasse no órgão. Em 1976, a proposta foi referendada por Silveira, o Brasil se candidatou e foi eleito para iniciar seu mandato como membro da $\mathrm{CDH}$ a partir de 1978. Com breves intervalos de tempo, desde então o Brasil tem sido um membro da $\mathrm{CDH}$ e do seu sucessor, o Conselho. ${ }^{17}$

\section{Considerações finais}

Em 1975, pela primeira vez, a CDH criou um subgrupo para investigar as denúncias de violações a um regime fora do contexto do colonialismo e racismo institucional. No decorrer da década, várias iniciativas contra o Chile de Pinochet ganharam força e a linguagem dos direitos humanos deu contornos à empreitada (assim como foi contornada por ela). Se o dossiê contra o Brasil fosse adiante ou se

\footnotetext{
17 Após sua eleição em 1977, o Brasil ocupou assento na CDH de forma ininterrupta por vinte anos, de 1978 a 1998. Ficou fora em 1999, mas voltou de 2000 a 2005, e depois, já no Conselho de Direitos Humanos, participou como membro de 2006 a 2011, de 2013 a 2015, e de 2017 a 2019. Ou seja, com os breves intervalos de 1999, 2012 e 2016, o Brasil participa do principal órgão de direitos humanos da ONU desde o final da década de 1970, quando ainda estava no regime militar. As listas dos membros da Comissão e do Conselho podem ser acessadas aqui: https://www.ohchr.org/EN. Acesso em: 11 mai. 2019.
} 
outro caso tivesse sido analisado, a pressão contra o regime militar talvez tivesse sido diferente - tal como aconteceu com a ditadura chilena de Pinochet.

O dossiê contra a ditadura na Comissão da ONU é significativo em pelo menos três aspectos. Primeiro, ele é um marco da maior atenção que a política externa brasileira começou a dar ao tema dos direitos humanos. O melhor exemplo disso é o próprio ingresso do país na Comissão, após o arquivamento do caso. Afinal, por que um regime autoritário como o Brasil da segunda metade da década de 1970 queria ingressar no principal órgão de direitos humanos da ONU? As motivações da diplomacia do governo Geisel eram complexas e envolviam o contexto do processo de abertura política. Entendo que a iniciativa brasileira de participar da CDH não foi resultado das pressões internas e internacionais em nome dos direitos humanos, como parte da literatura acadêmica sobre o assunto sugere (Belli, 2009).

128 A diplomacia da ditadura não cedeu às acusações e não passou a tratar as ONGs de forma diferente nos anos finais da ditadura. Para a ditadura militar, participar do principal órgão de direitos humanos da ONU fazia sentido não $a p e-$ sar da natureza do seu regime, mas porque era uma ditadura e tinha um projeto controlado de abertura. Ou seja, seria mais fácil lidar com eventuais novos casos contra o regime por dentro do sistema. Certamente, a experiência com as denúncias mostraram como um controle próximo das várias fases da burocracia onusiana poderia ser decisivo.

Em segundo lugar, o esforço do país em arquivar o dossiê fez parte de uma estratégia (bem-sucedida) sobre como lidar com as acusações contra o país. Os arquivos mostram que o caso recebeu atenção prioritária de Brasília e que estratégias consistentes foram elaboradas. A diplomacia da ditadura não foi meramente reativa às denúncias contra o país: o Ministério das Relações Exteriores acompanhou o dossiê em todas as etapas do processo, buscou e conseguiu 
influenciar o processo decisório tanto nas instâncias de representação estatal quanto junto aos especialistas independentes. A máquina burocrática se organizou, diversos ministérios se envolveram, estratégias foram debatidas e um complexo desenho e processos decisórios foram executados. A diplomacia da ditadura foi eficaz e empregou as mais variadas táticas pelos canais formais e informais, a fim de arquivar as denúncias de assassinato, tortura, prisões políticas e outras violações.

Por fim, a atuação brasileira nesse caso é um exemplo de como a política externa do período não passou incólume ao regime ditatorial vigente no país. Há uma bibliografia recente que está questionando como a atuação internacional do país foi afetada pelo aparato repressor da ditadura e o caso contra o regime na ONU merece atenção. Essas leituras críticas passam menos pela atuação profissional de diplomatas específicos e mais pela desconstrução de um discurso que isenta a política externa do regime de repressão que vigeu no país durante mais de duas décadas. Com o arquivamento do dossiê na CDH, findava-se o principal caso contra o regime militar apresentado no sistema de direitos humanos da ONU e uma das melhores chances de publicizar as atrocidades cometidas pelo autoritarismo brasileiro na Comissão. Os documentos do MRE sugerem que o material preparado pela Anistia era consistente e trazia denúncias que poderiam ter seguimento nos intrincados trâmites onusianos. Outras denúncias apresentadas contra o país não geraram tanto receio nos telegramas trocados pelos diplomatas, nem nos estudos preparados para a tomada de decisão do executivo nacional.

Um ano após o arquivamento do dossiê contra o Brasil, em 1977, a diplomacia estadunidense de Carter usava os canais bilaterais e multilaterais para acusar governos de esquerda e de direita que violassem direitos humanos. As ditaduras latino-americanas vizinhas estavam entre os 
alvos preferenciais. A CDH ganhou mais força a partir de 1977, quando a diplomacia brasileira já tinha conseguido desviar o foco do país. Apesar de o regime brasileiro continuar pressionado, o momento ideal no sistema da ONU tinha passado.

\section{João Roriz}

Doutor em direito internacional (USP), Professor de relações internacionais, Universidade Federal de Goiás (UFG).

\section{Bibliografia}

ALMEIDA, Paulo Roberto de. 2008. Do alinhamento recalcitrante à colaboração relutante: o Itamaraty em tempos de AI-5. In: MUNTEAL FILHO, Oswaldo; FREITAS, Jacqueline Ventapane; FREIXO, Adriano de (org.). Tempo negro, temperatura sufocante: Estado e sociedade no Brasil do AI-5. Rio de Janeiro: Contraponto, 2008, pp. 65-89.

ALSTON, Philip. 1992. The Commission on Human Rights. In: ALSTON, Philip (org.). The United Nations and Human Rights. New York: Oxford University Press, 1992, pp. 126-194.

AMNESTY INTERNATIONAL. 1972a. Report on Allegations of Torture in Brazil. Palo Alto: Amnesty International.

AMNESTY INTERNATIONAL. 1972b. Amnesty International in quotes. Palo Alto: Amnesty International.

BATISTA, David do Nascimento. 2010. Habitus diplomático: um estudo do Itamaraty em tempos de regime militar (1964-1985). Tese de Doutorado em Sociologia. Recife: UFPE.

BELLI, Benoni. 2009. A politização dos direitos humanos: o Conselho de Direitos Humanos das Nações Unidas e as resoluções sobre países. São Paulo: Perspectiva.

BERNARDI, Bruno Boti. 2017. Silence, hindrances and omissions: the Inter-American Commission on Human Rights and the Brazilian military dictatorship. The International Journal of Human Rights, v. 22, n. 9, pp. 1123-1143.

BRASIL. Comissão Nacional da Verdade. 2014. Relatório. Brasília, DF: CNV. v. 1.

CANÇADO TRINDADE, Antônio Augusto. 2000. A proteção internacional dos direitos humanos e o Brasil (1948-1997): as primeiras cinco décadas. 2a. ed. Brasília, DF: UnB. 
CARMO, Gessica Fernanda do. 2018. Os soldados de terno? ruptura, crise e reestruturação da diplomacia brasileira (1964-1969). Dissertação de Mestrado em Relações Internacionais. Campinas: Unicamp.

CASTILHO, Alessandra Beber. 2015. Diplomacia e repressão política: a atuação do Centro de Informações do Exterior e da Divisão de Segurança e Informações do Ministério das Relações Exteriores no Chile (1968-1973). Dissertação de Mestrado em Relações Internacionais. Rio de Janeiro: UERJ.

ECOSOC [Conselho Econômico e Social]. Resolução 1235 (XLII), E/4393, 6 de junho de 1967. Disponível em: https:/ / digitallibrary. un.org/record/214657. Acesso em: 24 jun. 2019.

ECOSOC [Conselho Econômico e Social]. Resolução 1503. (XLVIII), E/4832/Add.1, 27 de maio de 1970. Disponível em: https://digitallibrary. un.org/record/214705. Acesso em: 24 jun. 2019.

FERNANDES, Ananda Simões. 2018. Burocratas da dor: as conexões repressivas entre os órgãos de informação das ditaduras brasileira e uruguaia (1973-1985). Tese de Doutorado em História. Porto Alegre: UFRGS.

FERNANDES, Fernanda de Moura. 2007. De golpe a golpe: politica exterior e regime político no Brasil e no Chile (1964-1973). Dissertação de Mestrado em Relações Internacionais. Brasília, DF: UNB.

GASPARI, Elio. 2014. A ditadura encurralada. 2. ed. Rio de Janeiro: Intrínseca.

GREEN, James. 2009. Apesar de vocês: oposição à ditadura brasileira nos Estados Unidos. Tradução: S. Duarte. São Paulo: Companhia das Letras.

HARMER, Tanya. 2012. Brazil's cold war in the southern Cone, 1970-1975. Cold War History, v. 12, n. 4, pp. 659-681.

JENSEN, Steven L. B. 2016. The making of international human rights: the 1960s, decolonization, and the reconstruction of global values. Cambridge: Cambridge University Press.

KELLY, Patrick William. 2018. Sovereign emergencies: Latin America and the making of global human rights politics. Nova York: Cambridge University Press.

LAUTERPACHT, Hersch. 1950. International law and human rights. London: Stevens \& Sons Limited.

LINDGREN ALVES, José Augusto. 1994. Os direitos humanos como tema global. São Paulo: Perspectiva.

MAIA, Marrielle; LIMA, Rodrigo Assis. 2017. O ativismo de direitos humanos brasileiro nos relatórios da Comissão Interamericana de Direitos Humanos (1970-2015). Direito e Práxis, v. 8, n. 2, pp. 1419-1454.

MARQUES, Teresa Cristina Schneider. 2011. Militância política e solidariedade transnacionais: a trajetória política dos exilados brasileiros no Chile e na França (1968-1979). Tese de Doutorado em Ciência Política. Porto Alegre: UFRGS. 
MARQUES, Teresa Cristina Schneider. 2014. A interação entre a política doméstica do regime militar e a diplomacia: uma análise das relações Brasil-Chile durante o governo de Salvador Allende. Século XXI, v. 5, n. 1, pp. 31-48.

MAZOWER, Mark. 2009. No enchanted palace: the end of empire and the ideological origins of the United Nations. Princeton: Princeton University Press.

MRE. Ministro das Relações Exteriores. 1975. [Carta]. Destinatário:

[Ministro da Justiça, Armando Ribeiro Falcão]. [S. l.], 2 abr. 1975d. Comissão de Direitos do Homem das Nações Unidas.

MRE. Ministro das Relações Exteriores. 1976. [Informação para o Senhor Presidente da República]. Destinatário: [Presidente da República, Ernesto Geisel]. [S. l.], 20 jul. 1976k. Comissão de Direitos Humanos. Novo Dossier sobre o Brasil.

MRE. Embaixada do Brasil no Panamá. 1975. [Telegrama]. Destinatário:

[Secretaria de Estado]. [S. l.], 24 jan. 1975c. Comissão de Direitos do Homem. Grupo de Trabalho. Dossiê sobre o Brasil.

MRE. Delegação brasileira em Nova York. 1969. [Telegrama]. Destinatário:

[Secretaria de Estado]. [S. l.], 1 ago. 1969. Direitos Humanos $132 \quad$ Alegadas violações no Brasil.

MRE. Delegação brasileira em Genebra. 1973. [Telegrama]. Destinatário:

[Secretaria de Estado]. [S. l.], 19 set. 1973. Queixas contra o Brasil com relação aos direitos do homem.

MRE. Delegação brasileira em Nova York. 1974. [Telegrama]. Destinatário:

[Secretaria de Estado]. [S. l.], 26 fev. 1974b. Comissão de Direitos Humanos - Denúncias contra o Chile.

MRE. Delegação brasileira em Nova York. 1974. [Telegrama]. Destinatário:

[Secretaria de Estado]. [S. l.], 28 fev. 1974c. Comissão de Direitos Humanos. Queixas contra o Brasil.

MRE. Delegação brasileira em Nova York. 1974. [Telegrama]. Destinatário:

[Secretaria de Estado]. [S. l.], 17 ago. 1974f. Subcomissão sobre a Prevenção da Discriminação e Proteção de Minorias. Relatório do Grupo de Trabalho.

MRE. Delegação brasileira em Nova York.1974. [Telegrama].

Destinatário: [Secretaria de Estado]. [S. l.], 28 ago. 1974g. XXVII

Sessão da Subcomissão sobre a Prevenção da Discriminação e Proteção de Minorias.

MRE. Delegação brasileira em Genebra. 1975. [Telegrama]. Destinatário:

[Secretaria de Estado]. [S. l.], 22 ago. 1975e. Subcomissão sobre a Prevenção da Discriminação e Proteção de Minorias. 
MRE. Delegação brasileira em Genebra. 1976. [Telegrama]. Destinatário: [Secretaria de Estado]. [S. l.], 30 jan. 1976g. Comissão de Direitos Humanos. Resposta do governo brasileiro.

MRE. Delegação brasileira em Genebra. 1976. [Telegrama]. Destinatário: [Secretaria de Estado]. [S. l.], 3 fev. 1976h. 32ª Sessão da Comissão de Direitos Humanos. Dossiê Brasil.

MRE. Delegação brasileira em Genebra. 1976. [Telegrama]. Destinatário: [Secretaria de Estado]. [S. l.], 12 fev. 1976i.Comissão de Direitos Humanos. Dossiê sobre o Brasil.

MRE. Secretaria de Estado. 1974. [Telegrama]. Destinatário: [Delegação brasileira na ONU]. [S. l.], 14 maio 1974d. Candidatura dinamarquesa à Comissão de Direitos Humanos no $56^{\circ}$ Ecosoc.

MRE. Secretaria de Estado. 1974. [Telegrama]. Destinatário: [Embaixada brasileira em Moscou]. [S. l.], 12 ago. 1974e. Subcomissão sobre a Prevenção da Discriminação e Proteção de Minorias. Iniciativa contra o Brasil.

MRE. Secretaria de Estado. 1975. [Telegrama]. Destinatário: [Delegação brasileira em Genebra]. [S. l.], 21 jan. 1975b. Comissão de Direitos do Homem. Grupo de Trabalho. Dossiê sobre o Brasil.

MRE. Secretaria de Estado. 1976. [Telegrama]. Destinatário: [Delegação brasileira em Genebra]. [S. l.], 6 jan. 1976b. Comissão de Direitos Humanos. XXXII Sessão. Dossiê do Brasil.

MRE. Secretaria de Estado. 1976. [Telegrama]. Destinatário: [Delegação brasileira em Genebra]. [S. l.], 20 jan. 1976c. Comissão de Direitos Humanos. Resposta do governo brasileiro.

MRE. Secretaria de Estado. 1976. [Telegrama]. Destinatário: [Delegação brasileira em Genebra]. [S. l.], 22 jan. 1976d. Comissão de Direitos Humanos. Resposta do governo brasileiro.

MRE. Delegação brasileira em Genebra. 1976. [Telegrama]. Destinatário: [Secretaria de Estado]. [S. l.], 28 jan. 1976e. Comissão de Direitos Humanos. Resposta do governo brasileiro.

MRE. Secretaria de Estado. 1976. [Telegrama]. Destinatário: [Sem destinatário]. [S. l.], 16 mar. 1976j. Comissão de Direitos Humanos. 32 Sessão. Dossiê Brasil.

MRE. Secretaria de Estado. 1977. [Telegrama]. Destinatário: [Delegação brasileira em Genebra]. [S. l.], 1977a. Posição do Brasil no tratamento dos Direitos do Homem.

MRE. Secretaria de Estado. 1977. [Telegrama]. Destinatário: [Delegação brasileira em Genebra]. [S. l.], 8 mar. 1977b. Comissão de Direitos Humanos. 
MRE. Secretaria de Estado. 1974. [Telegrama]. Destinatário: [Delegação brasileira em Genebra]. [S. l.], 19 fev. 1974a. Comissão de Direitos Humanos. XXX Sessão. Item 12(b) da agenda. Queixas contra o Brasil. MUTUA, Makau. 2002. Human rights: A political and cultural critique. Philadelphia: University of Pennsylvania Press.

NAPOLITANO, Marcos. 2014. 1964: História do regime militar brasileiro. São Paulo: Editora Contexto.

PENNA FILHO, Pio. 2009. O Itamaraty nos anos de chumbo: o Centro de Informações do Exterior (CIEX) e a repressão no Cone Sul (19661979). Revista brasileira de política internacional, v. 52, n. 2, pp. 43-62.

PEREIRA, Anthony W. 2010. Ditadura e repressão: o autoritarismo e o Estado de direito no Brasil, no Chile e na Argentina. São Paulo: Paz e Terra.

PRADO, Mayra do. 2017. A atuação do Centro de Informações do Exterior (CIEX) do Itamaraty de 1966 a 1986: a reexternalização do conflito ideológico.

Dissertação de Mestrado em Relações Internacionais. São Paulo: Unesp. RORIZ, João Henrique. 2017. Clashing frames: human rights and foreign policy in the Brazilian re-democratization process. Revista brasileira de politica internacional, v. 60, n. 1, pp. 1-17.

SETEMY, Adrianna Cristina Lopes. 2013. Sentinelas das fronteiras: o Itamaraty e a diplomacia brasileira na produção de informações para o combate ao inimigo comunista (1935-1966). Tese de Doutorado em História Social. Rio de Janeiro: UFRJ.

SIMON, Roberto. 2021. O Brasil contra a democracia: a ditadura, o golpe no Chile e a Guerra Fria na América do Sul. São Paulo: Companhia das Letras. SPEKTOR, Matias. 2004. Origens e direção do pragmatismo ecumênico e responsável (1974-1979). Revista brasileira de política internacional, v. 47, n. 2, pp. 191-222.

SUB-COMMISSION on prevention of discrimination and protection of minorities, resolution 1 (XXIV), U.N. DOC. E/CN.4/1070 at 50-51. 1971. University of Minnesota Human Rights Library, Minneapolis. Disponível em: https://bit.ly/3AZKJ8r. Acesso em: 24 jun. 2019. TARDU, Maxime Edouard. 1980. United Nations response to gross violations of human rights: the 1503 procedure. Santa Clara law review, v. 20, n. 3, pp. 559-601.

TOLLEY, Howard. 1987. The UN Commission on Human Rights. Boulder: Westview Press.

UNITED NATIONS. 1947. Commission on Human Rights. Report to the Economic and Social Council on the First Session of the Commission held at Lake Success, New York, from 27 January to 10 February (document E/259). New York: United Nations. 
UNITED NATIONS. 1974. Question of the violation of human rights and fundamental freedoms, including policies of racial discrimination and segregation and of apartheid, in all countries, with particular references to colonial and other dependent countries and territories. Geneva: United Nations.

UNITED NATIONS. Commission on Human Rights. 1949. Report of the 5th session of the Commission on Human Rights to the economic and social council. New York: United Nations.

UNITED NATIONS. Economic and Social Council. 1946. Commission on Human Rights and Sub-Commission on the Status of Women. London: United Nations.

UNITED NATIONS. Economic and Social Council. 1966a. Measures for the speedy implementation of the United Nations Declaration on the Elimination of All Forms of Racial Discrimination. Disponível em: https:/ / digitallibrary. un.org/record/214191. Acesso em: 24 jun. 2019.

UNITED NATIONS. UN General Assembly. 1966b. Question of the violation of human rights and fundamental freedoms, including policies of racial discrimination and segregation and of apartheid, in all countries, with particular reference to colonial and other dependent countries and territories. Disponível em: https://digitallibrary.un.org/record/203273. Acesso em: 24 jun. 2019.

UNITED NATIONS. Subcommission on prevention of discrimination and protection of minorities. 1972. Report of the sub-commission on prevention of discrimination and protection of minorities to the Commission on Human Rights on its 25th session. New York: United Nations.

VRECHE, Carla Cristina. 2017. À luz da vela: o ativismo transnacional da Anistia Internacional durante o regime militar brasileiro (1964-1985). Dissertação de Mestrado em Sociologia. Dourados: UFGD. 
Os donos do silêncio

136

Lua Nova, São Paulo, 113: 103-136, 2021 
OS DONOS DO SILÊNCIO: A POLÍTICA EXTERNA DO REGIME MILITAR BRASILEIRO E A COMISSÃO DE DIREITOS HUMANOS DAS NAÇÕES UNIDAS

JOÃO RORIZ

Resumo: Ao contrário do que parte da literatura sobre política externa afirma, a diplomacia brasileira não passou incólume ao aparato repressor do regime militar. À medida que as críticas e os casos contra a ditadura se avolumavam em fóruns internacionais, a alta cúpula do regime definiu estratégias para lidar com as acusações de violações de direitos humanos. $\mathrm{O}$ artigo trata do caso contra o regime militar que tramitou entre 1974 e 1976 na Comissão de Direitos Humanos da ONU. O dossiê preparado pela ONG Anistia Internacional foi a principal ameaça contra o regime brasileiro na ONU e movimentou grandes esforços diplomáticos para seu arquivamento. As principais fontes do texto são documentos do Ministério das Relações Exteriores.

Palavras-chave: Ditadura; Direitos Humanos; Política Externa; ONU.

\section{THE OWNERS OF SILENCE: THE FOREIGN POLICY OF THE BRAZILIAN DICTATORSHIP AND THE UN COMMISSION ON HUMAN RIGHTS}

Abstract: Contrary to what part of the literature on foreign policy states, the Brazilian diplomacy did not go by untouched by the repressive apparatus of the military regime. As criticism and cases against the dictatorship grew in international forums, the top management of the military regime formulated strategies to deal with allegations of human rights violations. Using documents of the Brazilian Ministry of Foreign Affairs, this article presents the case against the Brazilian military regime heard at the United Nations Commission on Human Rights between 1974 and 1976. The dossier 
prepared by non-governmental organization Amnesty International was the main threat against the Brazilian dictatorship at the UN, devoting great diplomatic efforts for its archiving.

Keywords: Dictatorship; Human Rights; Foreign Policy; UN.

Recebido: 24/09/2019 Aprovado: 05/02/2021 